\title{
Mass Customization in Wireless Communication Services: Individual Service Bundles and Tariffs
}

\author{
Hong Chen and Louis-Francois Pau
}

\begin{tabular}{|l|l|}
\hline \multicolumn{2}{|l|}{ ERIM REPORT SERIES RESEARCH IN MANAGEMENT } \\
\hline ERIM Report Series reference number & ERS-2007-051-LIS \\
\hline Publication & August 2007 \\
\hline Number of pages & 25 \\
\hline Persistent paper URL & \\
\hline Email address corresponding author & hchen@rsm.nl \\
\hline Address & Erasmus Research Institute of Management (ERIM) \\
& RSM Erasmus University / Erasmus School of Economics \\
& Erasmus Universiteit Rotterdam \\
& P.O.Box 1738 \\
& 3000 DR Rotterdam, The Netherlands \\
& Phone: + 31104081182 \\
& Fax: $\quad+31104089640$ \\
& Email: info@erim.eur.nl \\
& Internet: www.erim.eur.nl \\
\hline
\end{tabular}

Bibliographic data and classifications of all the ERIM reports are also available on the ERIM website: www.erim.eur.nl 


\section{ERASMUS RESEARCH INSTITUTE OF MANAGEMENT}

\section{REPORT SERIES}

\section{RESEARCH IN MANAGEMENT}

\begin{tabular}{|l|l|}
\hline ABSTRACT AND KEYWORDS \\
\hline Abstract & $\begin{array}{l}\text { This paper presents results on mass customization of wireless communications services and } \\
\text { tariffs. It advocates for a user-centric view of wireless service configuration and pricing as } \\
\text { opposed to present-day service catalog options. The focus is on design methodology and tools } \\
\text { for such individual services and tariffs, using altogether information compression, negotiation } \\
\text { algorithms, and risk portfolio analysis. We first analyze the user and supplier needs and } \\
\text { aspirations. We then introduce the systematic design-oriented approach which can be applied. } \\
\text { The implications of this approach for users and suppliers are discussed based on an end-user } \\
\text { survey and on model-based calculations. It is shown that users can achieve desired service } \\
\text { bundle cost reduction, while suppliers can improve significantly their risk-profit equilibrium points, } \\
\text { reduce churn and simplify provisioning. }\end{array}$ \\
\hline Free Keywords & $\begin{array}{l}\text { mobile communication services, mass customization, individual tariffs, negotiation, } \\
\text { service configuration }\end{array}$ \\
\hline Availability & $\begin{array}{l}\text { The ERIM Report Series is distributed through the following platforms: } \\
\text { Academic Repository at Erasmus University (DEAR), DEAR ERIM Series Portal } \\
\text { Social Science Research Network (SSRN), SSRN ERIM Series Webpage } \\
\text { Research Papers in Economics (REPEC), REPEC ERIM Series Webpage }\end{array}$ \\
\hline Classifications & $\begin{array}{l}\text { The electronic versions of the papers in the ERIM report Series contain bibliographic metadata } \\
\text { by the following classification systems: } \\
\text { Library of Congress Classification, (LCC) LCC Webpage } \\
\text { Journal of Economic Literature, (JEL), JEL Webpage } \\
\text { ACM Computing Classification System CCS Webpage } \\
\text { Inspec Classification scheme (ICS), ICS Webpage }\end{array}$ \\
\hline
\end{tabular}




\title{
Mass Customization in Wireless Communication Services: Individual Service Bundles and Tariffs
}

\author{
Hong Chen, Louis-Francois Pau \\ Rotterdam School of Management, Erasmus University \\ P.O Box 1738, 3000 DR Rotterdam, the Netherlands \\ \{hchen,lpau\}@rsm.nl
}

\section{Acknowledgements:}

The authors would like to express their appreciation to the 22 members of the international discussion group "Personalized pricing of mobile service bundles" as well as to the people and organizations who helped with the distribution of the survey, especially the "International Telecommunication Users Group (INTUG)". The authors also thank the respondents who spent their time filling out the survey. 


\begin{abstract}
This paper presents results on mass customization of wireless communications services and tariffs. It advocates for a user-centric view of wireless service configuration and pricing as opposed to present-day service catalog options. The focus is on design methodology and tools for such individual services and tariffs, using altogether information compression, negotiation algorithms, and risk portfolio analysis. We first analyze the user and supplier needs and aspirations. We then introduce the systematic design-oriented approach which can be applied. The implications of this approach for users and suppliers are discussed based on an end-user survey and on model-based calculations. It is shown that users can achieve desired service bundle cost reduction, while suppliers can improve significantly their risk-profit equilibrium points, reduce churn and simplify provisioning.
\end{abstract}

Keywords: mobile communication services, mass customization, individual tariffs, negotiation, service configuration

\title{
1. Introduction
}

This paper presents the progress and challenges of the research and needed support tools in mass customization of mobile/wireless communication services.

Recent research in mass customization has primarily focused on the customization of physical products such as clothing (e.g. footwear, garments, prêt à porter), consumer electronics (e.g. watches, laptops), etc., and on user design toolkits for such customizations (Abou-Jaoude \& Kung, 2005; Au \& Goonetilleke, 2005; Franke \& Pille, 
2004; Ogawa \& Piller, 2006; von Hippel, 2005). Services differ from physical goods in their intangibility, perishability, heterogeneity and in the inseparability of production from consumption (Zeithaml, Parasuraman, \& Berry, 1985). Mass customization of services is rather limited and applications are widely spread across different industries such as education, finance, health care, etc.; the corresponding research publications have focused on mass customization strategy (Gabriel, Gersch, \& Weber, 2006; Grenci \& Watts, 2007; Lampel \& Mintzberg, 1996), customization frameworks, processes and customization approaches under specific contexts (Huang \& Lin, 2005; Winter, 2001), and customer value perception (Prahalad \& Ramaswamy, 2004).

Current practices of mass customization in the mobile communication industry mainly focus on the industrial design of the wireless terminals, on user interfaces and sometimes on software based feature selection; see e.g. Sigala (2006) for customers' perceived value dimensions (e.g. functional, social, and emotional) of mass customized "mobile phone + services" and implications for suppliers in conducting a customer valuebased market segmentation. Some mobile terminal suppliers have made mass customization of their designs their key intellectual property rights (IPR) based business model. This is accomplished via common design platforms that help third parties produce competing customized products (e.g. Ericsson Mobile Platforms AB, Modelabs, Qualcomm).

With regard to public mobile services which involve the network infrastructure for the production of such services, mass customization remains limited despite mobile users numbering in excess of 2 Billion. Public operators usually offer 5-10 generic service bundles which are sold "unmodified" to anyone and include only basic service functions that most customers are expected to use, such as voice communication, SMS; each bundle corresponds to a set of tariffs. User chooses a bundle, signs a contract 
(usually for 1 or 2 years) and pays a fixed monthly fee, which may cover a maximum usage of voice minutes, SMS, MMS or a certain amount of data traffic, plus limited customer support and wireless terminal amortization. Costs for usage exceeding the default service usage limits vary among bundles. There is no interaction between the supplier and the user, other than when a user is choosing from a supplier's defined catalog of services. Different suppliers offer almost the same bundles except for prices, support functions and upgrades. Personalization of the services is limited to a few discrete user choices relating to the same bundles.

\section{Scope of the paper}

This paper and other related one's (Chen \& Pau, 2006, 2007a, 2007b, 2007c; Pau \& Chen, 2006), advocate for a much bolder user-centric view of wireless service configuration and pricing. The goal is to let all users who wish to manage service and content access themselves, define which functions, content and price they will accept, waiting for competing suppliers to bid for it. Once a supplier has been chosen and has accepted, he must provide such a mass customized bundle for a duration chosen by the user.

Obviously not all users want to take this customization into their own hands, in that many will just be happy with the generic catalog bundles and the lack of transparency attached to the provisioning costs and quality of service (QoS) of such generic bundles.

Thus the real challenge behind mass customization of mobile communication service and content bundles is, akin to general governance concepts, how much the user 
as a stakeholder needs to know, and how much the supplier is willing to reveal, about the infrastructure characteristics and operations.

A second challenge is to establish how the laws of large numbers can actually benefit the supplier who is willing to offer individual bundles and tariffs, by increasing user loyalty over time, enhancing the service demands, and reducing the financial and operational risks.

Thus this paper systematically analyzes the user and supplier needs and aspirations, benefits and risks, as a result of a proposed negotiation process supported by the corresponding tools. The implications of mass customization of mobile services are studied both via user surveys and via quantitative tools.

The paper is organized as follows: Section 3 analyzes user and supplier needs and expectation from mass customized mobile services; Section 4 summarizes the progress of a series of research we have conducted under the title "individual tariffs", which provide methodology and models to design mass customized wireless services and tariffs; Section 5 discusses the implications of individual services and tariffs for both the users and the suppliers; the analysis is based both on the results of a survey and on model based calculations; Section 6 discusses the open research issues; Section 7 concludes the paper.

\section{User and supplier needs and expectations from mass customized mobile services}

\subsection{User needs and expectations}

As mobile wireless becomes the dominant communications access technology worldwide, mobile services, especially value added services are growing in an explosive manner. User's needs and expectations from mobile services are changing. According to 
a worldwide survey conducted by the Rotterdam School of Management (Chen \& Pau, 2007c):

- Users are demanding specific service bundles that meet their unique demands; there is a wide variety of needs but also significant overlap (in terms of proposed applications and services) amongst individual users;

- Users want to reduce cost and simplify their service bundles when given the opportunity to personalize their service bundles and tariffs. This is reflected in the answers of $51 \%$ of the respondents who consider personalized service bundles and tariffs to be a cost reduction feature; while the rest consider it as a life style feature $(28 \%)$ and productivity feature (10\%). Regarding the pricing, $47 \%$ of the respondents would pay less than $50 \%$ of the original price when the number of service features in the service bundle is reduced by $50 \%$; $40 \%$ of the respondents will pay exactly half; and $13 \%$ of the respondents are willing to pay more than half;

- Users are demanding greater flexibility in contract length. The average ideal contract length is 6.8 month when the respondents can define the contract length themselves;

- Users are willing to spend time on personalizing a service. The majority of the respondents chose 30 minutes (22\%) and 1 hour (41\%).

\subsection{Supplier needs and expectations}

At the same time, the public suppliers in the mobile communications industry are facing:

- A continuously increased competition which was brought about by deregulation, privatization and liberalization (Geddes, 2000; Noam, 1983; Pau, 2002; Xu \& Pitt, 2002); the competition is both technological, in that e.g. fixed telephony is 
decreasing in proportion vs. other access technologies, as well as market based in that marketing and price pressure have major impacts while the number of suppliers increases;

- A fundamental layering introduced by the $3^{\text {rd }}$ Generation Partnership Project (3GPP) consisting of access networks, transport networks, and service layers, so that one given supplier may not have to own and operate all three with the related huge complexities;

- Largely saturated markets for wireless communications in early adopter geographical zones, with huge marketing costs, high churn rates and high customer retention costs as pitfalls (Wieland, 2006)

- A technology and customer push for converged services; here the meaning of convergence is two fold: the convergence amongst various access technologies $(2 \mathrm{G}, 2.5 \mathrm{G}, 3 \mathrm{G}, \mathrm{B} 3 \mathrm{G}$, WiMax, fixed) and the convergence of access, content and applications;

- High pressure on overstaffed incumbent operators to reduce operational processes and costs, even outsourcing many wireless service operations to systems suppliers or integrators;

- Insufficient investments in service creation, commoditization of key infrastructure elements, in content access rights, etc ...

The segmentation of mobile services into limited generic bundles can no longer satisfy the needed actions from the above trends, as they fundamentally have diminishing returns from ever increasing provisioning complexities. It is high time that user-centric mass customization, with user-supplier interactions, is introduced in mobile communication services; it will fundamentally allow the suppliers to achieve a higher granularity of their service and access components and thus finally to clinch more stable 
revenues from managed services rather than from managing network capacity exposed to user churn.

\section{Modeling the user, the supplier and their interactions in the context of mass customized mobile services and tariffs}

\subsection{Individual services and tariffs}

Under the context of mass customization of mobile services, we define individual service and tariffs as the regulatory protected ability for an identified user to obtain from a service provider, by a bilateral specific contract, a set of service and related content specific prices corresponding to a user request specified with a service demand profile and some duration. In short, the user will have tariffs unique to him depending on the services he requires in terms of quality and quantity.

The research on individual bundles and tariffs can be divided into three major areas:

1.) The study of users from the perspective of mass customized consumer behavior in services (different from products) (Chen \& Pau, 2006).

2.) The study of suppliers exposed to mass customized services and tariffs which focus on service and content bundling models, service provisioning, and on churn reduction problems (Chen \& Pau, 2006, 2007a; Pau \& Chen, 2006).

3.) The study of the interactions between a user and a supplier for individual service bundles and prices. The focus is on negotiation models, with all refinements including risk analysis; and on the operational environment for the deployment of such models in view of the large number of negotiations (Chen \& Pau, 2006, 2007a, 2007b; Pau \& Chen, 2006). 
We take a utilitarian approach when modeling the users and the suppliers.

\subsection{Modelling the users}

The user, instead of being fully rational, has "bounded rationality" (Simon, 1957). He tries to optimize his utility but in a simple way. We propose that the user builds his utility function based on a set of "perceived attributes" of a mobile service. The "perceived attributes" are a reduced, e.g. 3 dimensional mapping of the e.g. $20+$ service

attributes defined by the service provider using full technical specifications in the "service design space". The mapping is determined by either user surveys, previous customer information, and/or actual service usage as communications networks offer unique self-monitoring capabilities not found in other application areas for mass customization. We introduced a computational method to design such service specific perceived attributes, using principal component analysis adapted in a specific way (Pau \& Chen, 2006).

In the reduced "perceptual space" constructed by the perceived attributes, the user's utility function is defined as the Euclidian distance between a point ideal to him (target point) and the supplier's service bundle offer. The user maximizes his utility by minimizing the distance, subject to his social and economic constraints. He uses satisficing rules in decision making.

\subsection{Modelling the supplier(s)}

The supplier is considered to be a profit maximizing firm, with detailed modeling of an incremental customer's usage of infrastructure, content, management and other resources. The supplier makes decisions in the "service design space". His decision variables are primarily related to parameters of the technical specifications and configuration of a service (e.g. parameters related to QoS); these technical details are often beyond the interests or understanding of an ordinary user. The supplier's utility 
function is defined as the incremental profit from serving the demand of an additional user, which is the user's bid price minus all non-financial costs corresponding to the userrequested customized service and content characteristics. The utility function of a supplier and the applicable constraints and configuration options can be very complex; it has a lot non-linearities due to the underlying cost items and technology jumps involved in providing the service (Chen \& Pau, 2007a).

\subsection{The interaction between individual users and a supplier around individual tariffs and bundles}

The service personalization and tariff negotiation processes can be modeled by different multi-stage non-cooperative games (Chen \& Pau, 2006; Pau \& Chen, 2006). The user and supplier exchange technical, service and price attributes of a mobile service bundle as requested initially by the user, in a "service design space". They take turns to optimize with constraints their own utilities in each stage of the game. We define an equilibrium as a situation in which both the user and the supplier are satisfied with the negotiation result and agree to sign a contract. Stackelberg games are introduced when the user and the supplier have different bargaining power; the leader has the advantage of moving first. It can be a 1-on-1 or 1-on-N game when the supplier is negotiating with one individual user or a user community (Chen \& Pau, 2007a; Pau \& Chen, 2006).

In practice, such a Stackelberg equilibrium determination cannot obviously be carried out for any user with any supplier. But each operator will normally have all the information needed as well as the computation power to generate, e.g. in look-up table format most of the equilibrium cases, or non-contract cases, to be expected in a given market. 


\subsection{Risk analysis}

As they are driven by mass diversity in needs and willingness to pay, the userspecific service bundles and tariffs bring uncertainty to the supplier's profit: some of them generate profits; others may bring losses. This uncertainty can be reduced if the supplier pools together a large group of users whose preferences follow certain distributions. Note that revenue assurance techniques inspired from the insurance industry can be developed and used. In our research, we apply such statistical methods and techniques in analyzing the consequences and implications when the supplier is offering certain services to specific groups. For example, in the numerical case we designed (see Section 5 for details), we calculated the expected profit, value at risk (VaR) and percentage of contracted equilibria using the Monte Carlo method; the basic assumption is that a random user has consistent characteristics to a surveyed group. Such analysis is necessary to give the supplier basic business guarantees to enter individual tariff agreements. Furthermore, the supplier can adjust the parameters in the decision rules which are used in the negotiation; the adjustment can be based on profit vs. risk from the obtained risk statistics (Chen \& Pau, 2007a). If the supplier has a risk adverse profile, the above calculations produce estimates of the proportion of potential customers that no contracts will be signed with because such customers might have requests that represent the risky service bundles or usage profiles; in such a case, laws of competition should allow such users to find a competing supplier with a different risk profile.

\section{Implications for users and supplier}

Section 4 provided a systematic design-oriented approach regarding "how to achieve mass customized individual service bundles and tariffs". In this section, we give 
estimations of the implications, benefits and costs, when the users and the supplier commit to individual services and tariffs. These estimates are based both on the end-user survey reported in (Chen \& Pau, 2007c), and on model based equilibrium and risk calculations (as explained in Section 4 ):

- There were 13 questions in the survey; each focused on different aspect of user preferences regarding individual tariffs. The questions were also chosen in such a way that by nesting them, some estimates of key implicit indicators could be computed. Overall there were 102 respondents worldwide; the majority of them were end-users and researchers.

- With respect to the model-based calculations, we use a quasi-realistic operator model with non-linear wireless technology provisioning options, as well as user utility determinations from a survey group of 600 persons. Furthermore the model calculations include full Monte Carlo simulation, value at risk determination and realistic discretized decision variables on service attributes.

\section{Total traffic change}

Total traffic change can be estimated as the joint effect of the changes in communication patterns and changes in the number of service bundle features due to personalized configurations.

Changes in communication patterns are measured in the number of contacts, communication frequency and duration. The survey shows that about one-third of the respondents will not change their current behavior; about $60 \%$ of the respondents consider a slight increase up to $50 \%$. On average, the increases will be $16 \%$ (number of contacts), $20 \%$ (communication frequency) and 34\% (communication duration). These increases will lead to increased service bundle usage and network traffic demands. If we assume network traffic changes linearly with the changes in communication patterns, 
Ceteris paribus, then the increases in the number of contacts, communication frequency and communication duration will lead to an increase in the network traffic demand of: $(1+16 \%) *(1+20 \%) *(1+34 \%)$. i.e. $187 \%$.

On the other hand, personalization with service design put eventually in the hands of the users allows simplification of the services. If we assume the amount of network traffic is proportional to the number of features of the personalized service configuration, simplification could lead to a decrease in network traffic. The survey result indicates that $70 \%$ of the respondents considered a personalized service should be simpler when compared to a complete version of the service bundle; $20 \%$ respondents would keep it unchanged and $10 \%$ wanted more features. The expected change in the number of service features can be calculated from the weight of each group. We assess three scenarios, where the expected changes in the number of service features in the personalized service bundle are low, medium and high; see Table 1 (Here $25 \%$ means that the personalized service configuration will keep $25 \%$ of the features of the original service, $100 \%$ means unchanged, $175 \%$ means the personalized service configuration will add $75 \%$ more features to the original service bundle.) As it is shown in Table 1, in the low scenario, the result of personalized service configurations is a reduction of $50 \%$ of the original service bundle features.

Table 1: Different scenarios regarding the number of service bundle features and traffic change

\begin{tabular}{|l|c|c|c|}
\hline & \multicolumn{2}{|c|}{ Relative changes in the number } \\
& \multicolumn{2}{|c|}{ of service design features } \\
\hline Scenarios & Low & Medium & High \\
\hline Respondents want simplification (70\%) & $25 \%$ & $50 \%$ & $75 \%$ \\
\hline
\end{tabular}




\begin{tabular}{|l|c|c|c|}
\hline $\begin{array}{l}\text { Respondents want to keep service design unchanged } \\
(20 \%)\end{array}$ & $100 \%$ & $100 \%$ & $100 \%$ \\
\hline Respondents want more features (10\%) & $125 \%$ & $150 \%$ & $175 \%$ \\
\hline $\begin{array}{l}\text { Expected change in the number of service bundle } \\
\text { features }\end{array}$ & $50 \%$ & $70 \%$ & $90 \%$ \\
\hline
\end{tabular}

Given the above estimations, the total traffic change can be estimated under different scenarios. In the low scenario, the total amount of network traffic will decrease about $7 \%$. In the other two scenarios, there will be a growth in network traffic. See Table 2.

Table 2: Total traffic changes under different scenarios

\begin{tabular}{|l|c|c|c|}
\hline Scenarios & Low & Medium & High \\
\hline Traffic changes due to changes in communication patterns & \multicolumn{2}{|c|}{$187 \%$} \\
\hline Traffic changes due to changes in the number of features after & $50 \%$ & $70 \%$ & $90 \%$ \\
service design personalization & & & \\
\hline Total change in network traffic & $93 \%$ & $131 \%$ & $168 \%$ \\
\hline
\end{tabular}

If we assign a probability to the each of the scenarios from Table 1, i.e. low (0.3), medium (0.4) and high (0.3), the expected network traffic will be $131 \%$, which is a $31 \%$ increase from the previous situation which does not allow service design configuration and no individual tariffs.

\section{Churn rate}

Churn rate is defined as the percentage of subscribers who leave the contractual relationship with one supplier during a given period (e.g. 1 month). "Net churn" measures 
the overall loss of subscribers, while "Gross churn" measures the absolute loss. Net churn $(\%)=[$ Gross churn $(\%)$-New contracts $(\%)]$ (see http://en.wikipedia.org/wiki/Churn_rate). Here we only consider "Gross churn".

By allowing flexibility in the length of individual service bundle contracts, the supplier may have a shortened average contract length from the users compared to current dominant 12 or 24 months terms (with or without new mobile terminal). On one hand, it becomes easier for the users to switch network operators. But on the other hand, personalization can greatly improve user satisfaction, which in turn will reduce churn. This could mean that more users would like to prolong or renew the contracts with the same supplier of an individual service bundle when the previous contract expires.

According to Wireless Intelligence (Wieland, 2006), and spot data from wireless operators worldwide, the churn rate for mobile subscribers or prepaid users usually falls in the interval $1.5 \%-3 \% /$ month, with operator, bundle and country specifics. We estimate the gross churn rates under two scenarios -- $1.5 \%$ and $3 \%$ monthly churn rates; see Table 3. The corresponding yearly gross churns are calculated for reference purposes. Using the result from the survey which indicated an average individual tariff contract length of 6.8 months, the 7 month gross churn rate (rounded up from 6.8) can be calculated.

These data can serve as indicators for individual tariffs: by introducing mass customized service personalization for service and content bundles, and individual tariffs, the users accepting such a contract would NOT churn within 7 months. This means that for that sub-category of users, churn rate is certainly less than $10.4 \%$ under a low churn rate scenario for all users, and less than $19.2 \%$ under a high churn rate scenario for all users. 
Table 3: Churn rate estimations

\begin{tabular}{|c|c|c|}
\hline & Scenario low churn & Scenario high churn \\
\hline Monthly gross churn rate & $1.5 \%$ & $3 \%$ \\
\hline Yearly gross churn rate & $16.59 \%$ & $30.62 \%$ \\
\hline 7 months gross churn & $10.04 \%$ & $19.20 \%$ \\
\hline
\end{tabular}

\section{Changes in "price/bit"}

Changes in price per bit can be approximated by the following formula around a given point:

Derivative $($ price $/$ bit $)=[\mathrm{d}($ price $) *$ bit - price $* d($ bit $)] /$ bit $^{2}=\mathrm{d}($ price $) /$ bit - price $* d($ bit $) / b^{2}{ }^{2}$ Consider the scenario that as a result of the personalization of the service bundle configuration, the number of service features is reduced to $50 \%$ of the complete version of service and content bundle. According to the processed answers from the survey, the expected price the user is willing to pay will change to 0.4450 of the original price (of the complete version). The traffic under this (low) scenario will change to 93\% (see Table 2) of the original service and content bundle traffic. A rough estimation of the changes in (price/bit) ratio by compounded derivatives is:

$\left[\left(-0.5550 *\right.\right.$ price/bit - price* $(-0.0643) \mathrm{bit} / \mathrm{bit}^{2}=-0.4907 *$ (price/bit) $]$.

Thus price/bit is decreasing by almost half in this scenario to the benefit of the user if individual tariffs are adopted.

\section{Service configuration \& tariff negotiation}

From the survey, $23 \%$ of the respondents will pay less when they are offered to do the service design personalization themselves, as compared to the same service design managed by the operator. Suppliers can earn extra revenue by offering service 
configuration assistance for this group of subscribers. About half of the respondents would like to be actively involved in service configuration and tariff negotiation. The high willingness to spend about 1 hour on self-configuration shows eagerness to differentiate and save if cost savings can be generated and/or or unique service features can be chosen. Suppliers can also save costs from those who configure services for themselves.

\section{User and supplier benefits and risks from a case with quantitative analysis}

1.) The case: we designed a service bundle in the mobile music area (see details in (Pan \& Chen, 2006) and applied the above mentioned methods and models for service personalization and tariff negotiation. We developed a tool to automate the negotiation process for services and tariffs, along with the risk assessment.

2.) User benefits: our numerical results on that case show that users achieve a $370 \%$ gain in their utilities in the mass customized mode compared to the initial utilities derived from the selection of a sufficient generic service bundle. Figure 1 illustrates the negotiation between a user and a supplier modeled by the proposed Stackelberg game part of the toolset. The circles represent the user's requests and the crosses represent the supplier's counter proposals; the conclusive negotiation outcome is shown by point "Stakelberg EQ". The coordinates of each point represent the utilities of the user and the supplier. The user achieves a much better result when compared to the non-negotiable tariff illustrated by point "public offer" in the Figure 1. For the complete numerical case, see Chen \& Pau(2007a) and Pau \& Chen (2006). 


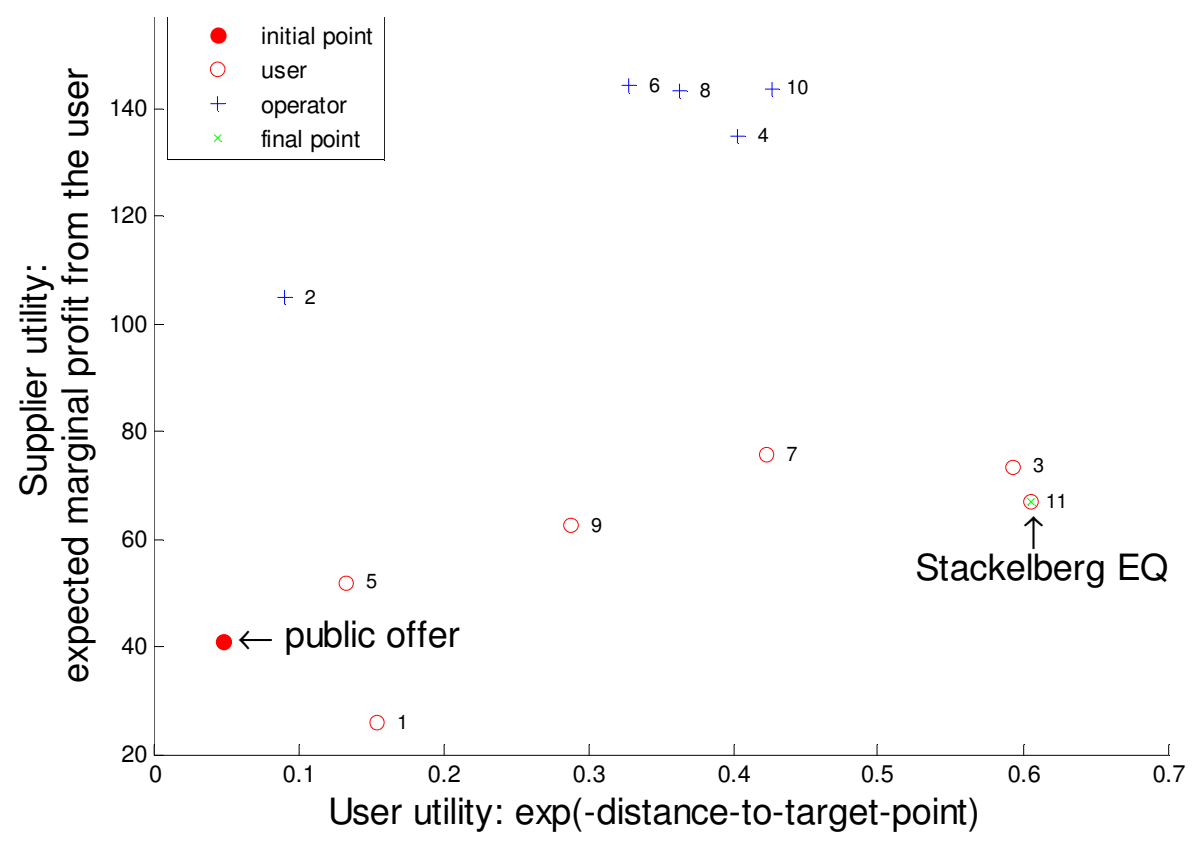

Figure 1: The negotiation process between a user and a supplier in the mobile music case

3.) Supplier benefits: at the same time, the supplier is able to adjust parameters to achieve a higher profit than with non-negotiable tariffs according to the risk he is willing to take. Figure 2(a), (b), (c) give a simplified illustration on how the adjustment of the parameter "minimum profit threshold" affects the percentage of contracted equilibria, the expected profit and the VaR. The effects of the adjustment of this parameter "minimum profit threshold" on the supplier's total expected profit and total risk are shown in Figure 2(d). An optimal solution where the supplier can achieve maximum profit with minimum risk may not exist. The supplier must then base his decision on an equilibrium compromise between the total risk he is willing to take and the total expected profit corresponding to that revenue. In practice, the shape of the curves can be much more complex, see (Chen \& Pau, 2007a; Pau \& Chen, 2006) for further details. 


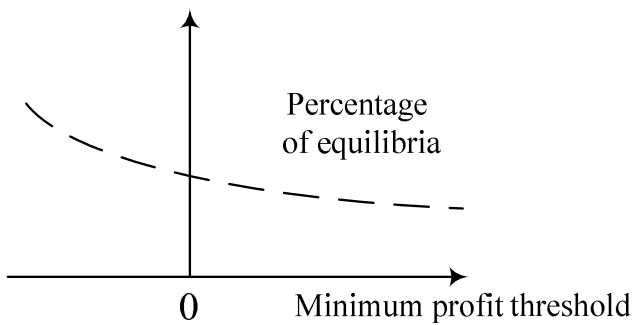

(a) Adjusting "Minimum profit threshold" affects "Percentage of equilibria"

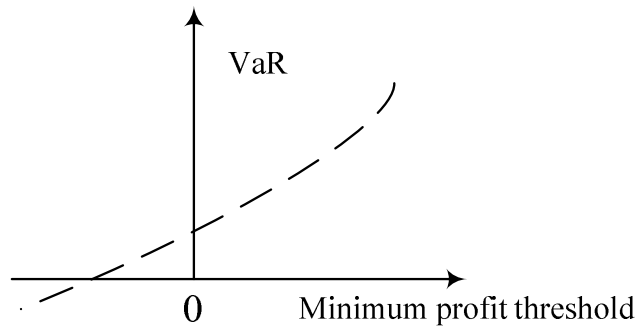

(c) Adjusting "Minimum profit threshold" affects "VaR"

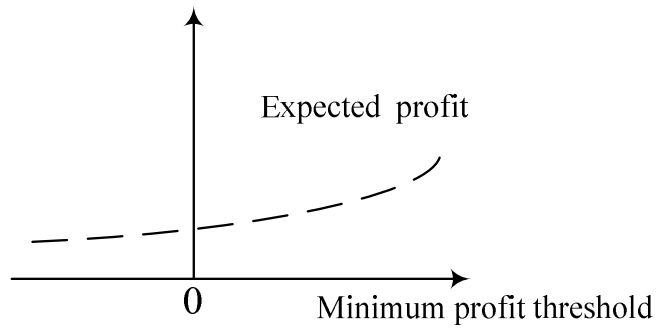

(b) Adjusting "Minimum profit threshold" affects "Expected profit"

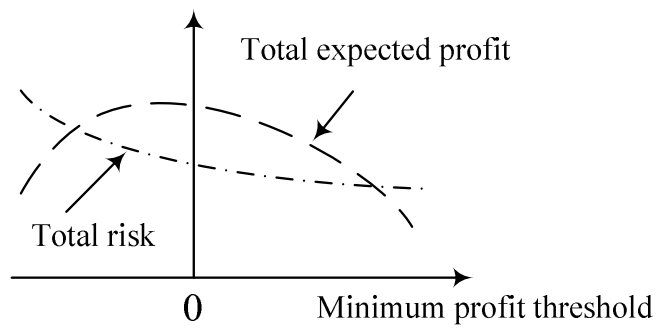

(d) Adjusting "Minimum profit threshold" affects "Total expected profit" and "Total risk"

Figure 2: Supplier can adjust the parameter "Minimum profit threshold" to achieve different results.

Using the same tools, we are looking into the mass customization of a generic service bundle but with an emphasis on only very basic service elements such as voice usage, SMS usage, contract price and contract duration. This means that end users can freely negotiate the personal usage of a catalog generic service. The fact that such a case can readily be investigated shows the power of the tool.

\section{Summary}

To summarize, mass customized wireless individual services and tariffs can help the users reduce cost, which is the main concern of more than half of the respondents to the user survey. For the supplier, individual services and tariffs may lead to an increase in traffic demand but with less complexity in over- or under-provisioning. Furthermore, individual tariffs offer the supplier flexibility to achieve better control of their goals in terms of market share, profit level and risks by a portfolio approach. Additionally, the 
supplier can benefit from extra revenues and reduced costs by helping, as an additional cost on top of the bundle, users who cannot themselves configure their individual service attributes. Regarding the churn rate, only the upper limit can be estimated, and it shows a significant reduction vs. present churn for generic services; the actual churn rate should be even lower because of the improved customer satisfaction and loyalty.

\section{Open research issues}

\section{Mass customization support tool}

The users want to be passively or actively involved in service personalization and tariff negotiation, but in all cases it is necessary for the supplier to have a set of tools to automate the process (see Section 5 above). A tool should function either in a simplified mode without much involvement by the users (e.g. users only provide simple service feature, price and contract duration wishes) or in an interactive mode where users actively participate in the service design personalization and negotiation. Furthermore, the tools should all provide risk assessments for the supplier when selecting different negotiation parameters and decision criteria. We have developed and implemented a prototype of such tool (Pau \& Chen, 2006) but it is not yet complete. The open issues are:

- how to implement the tool in a complex operational environment coupled to the OSS and rating engines;

- how to integrate the tool seamlessly into the supplier's service provisioning infrastructure;

- how to provide customer support to users of the mass customized service bundle once contracted. 


\section{User behavior}

From the survey result, still half of the respondents prefer a flat rate for all the services; it will be valuable to find out the main reason behind the preference.

We have done some basic research regarding the "simplification" concerns of the users when they do not select a flat rate. The solution is a "service design space" for the supplier and a "perceptual space" for the user, the latter being a reduced mapping of the former (Pau \& Chen, 2006). However, there is no immediate solution for what should be included in the design elements so that the perceived attributes of a service meet the user's demands.

The perception of individual services and tariffs as a cost reduction / life style / productivity improvement feature implies different user behaviors during the service configuration and tariff negotiation process. Our previous study used a coarse method by assuming all the users have a similar form of utility function, or that their preferences belong to a common utility distribution (Chen \& Pau, 2006). Further research can be done by identifying different utility functions for different categories of users.

\section{Churn}

Given the averaged ideal contract length for a mass customized service bundle and individual tariff (i.e. about 7 months), what still needs to be investigated is the specific churn rate for users of such individual services and tariffs alone, once compounded back to a monthly churn rate for such users, over a number of cycles of individual tariff contracts. This analysis should clarify how much smaller the specific churn rates would be for these specific users than the observed ones under the two scenarios in Section 5. Some early reports from industry (Wieland, 2006) show that by allowing very preliminary levels of personalization, operators can already greatly reduce churn. 


\section{Risk}

There are a lot of distribution uncertainties to be addressed when using individual tariffs:

- uncertainty that comes from user preferences;

- uncertainty that comes from user characteristics, which are hidden and driven by social issues such as affordability;

- uncertainty that comes from the supplier's service provisioning cost model due to lack of data and technical system failures.

Classic statistical analysis such as value at risk (VaR) may not provide good estimate of events with small probabilities but big impacts. Currently, we are trying to embed extreme value theory into the tools, which may safeguard the supplier from such risks.

\section{Conclusions}

This paper contributes to the research about mass customization of services by introducing the methods and models which can be applied in the mass customization of mobile communications services and tariffs.

The model-based quantitative analyses show that the adoption of personalized service bundles and tariffs can be beneficial to both the users and the suppliers. As the end-user survey has already indicated that there is a critical mass of the population who are willing to adopt mass customized services and tariffs, it is up to the suppliers to take the challenges to bring it into reality. In consequence when mobile operators will offer better responsiveness to their customers in terms of operations transparency, as well as governance to them as stakeholders, the sustainable financial performance of these operators will gain from mass customized service bundles and tariffs. 


\section{References:}

Abou-Jaoude, G., \& Kung, S. (2005). The Science of Fit in Garment MC. Proceedings of the 3rd Interdisciplinary World Congress on Mass Customization and Personalization, Advanced Manufacturing Institute, HKUST, Hong Kong.

Au, Y. L. E., \& Goonetilleke, R. S. (2005). Comfort characteristics of ladies' dress shoes. Proceedings of the 3rd Interdisciplinary World Congress on Mass Customization and Personalization, Advanced Manufacturing Institute, HKUST, Hong Kong.

Chen, H., \& Pau, L.-F. (2006). Individual Tariffs for Mobile Communication Services. Proceedings of the 16th Biennial Conference of the International Telecommunications Society, Beijing. Available www.its2006bupt.org.

Chen, H., \& Pau, L.-F. (2007a). Individual Tariffs for Mobile Service and Content Bundles: Analysis of Operator Business and Risk Consequences. Accepted by the 6th International Conference on Mobile Business (ICMB2007), Toronto, Canada Proceedings by IEEE Computer society.

Chen, H., \& Pau, L.-F. (2007b). Individual Telecommunication Tariffs in Chinese Communities. To appear in W. Huang, Y. L. Wang \& J. Day (Eds.), Global Mobile Commerce: Strategic Perspectives and Implementation Cases Hershey, USA: Idea group.

Chen, H., \& Pau, L.-F. (2007c). "Personalized Pricing of Mobile Service Bundles": Survey Design \& Key Findings. Rotterdam: Rotterdam School of Management. ERIM working paper.

Franke, N., \& Pille, F. (2004). Value Creation by Toolkits for User Innovation and Design: The Case of the Watch Market. Journal of Product Innovation Management, 21(6), 401-415. 
Gabriel, R., Gersch, M., \& Weber, P. (2006). Mass Customization as an adequate strategy for Education-Services. Proceedings of the World Conference on ELearning in Corporate, Government, Healthcare, and Higher Education. Chesapeake, VA: AACE.

Geddes, R. (2000). Public Utilities. In G. D. Geest \& B. Bouckaert (Eds.), Encyclopedia of Law and Economics (Vol. III The Regulation of Contracts, pp. 116-205). Cheltenham: Edward Elgar.

Grenci, R. T., \& Watts, C. A. (2007). Maximizing customer value via mass customized econsumer services Business Horizons, 50(2), 123-132.

Huang, E. Y., \& Lin, C. Y. (2005). Customer-oriented financial service personalization. Industrial Management \& Data Systems, 105(1), 26-44.

Lampel, J., \& Mintzberg, H. (1996). Customizing customization. Sloan Management Review, 38(1), 21-30.

Noam, E. M. (1983). Telecommunications regulation today and tomorrow. New York: Law \& Business.

Ogawa, S., \& Piller, F. T. (2006). Reducing the Risks of New Product Development. MIT Sloan Management Review, 47(2), 65-71.

Pau, L.-F. (2002). The communications and information economy: issues, tariffs and economics research areas. Journal of Economic Dynamics and Control, 26(9-10), 1651-1675.

Pau, L.-F., \& Chen, H. (2006). Individual tariffs for mobile service bundles: a negotiation calculation tool in Joaquim Filipe, Thomas Greene (Eds), Proc .2006 IEEE/ACM Intl conference on e-Business ICE-B 2006, Setubal, Portugal, INSTICC Press, ISBN 972-8865-62-7, pp 31-37 
Prahalad, C. K., \& Ramaswamy, V. (2004). The Future of Competition: Co-Creating Unique Value with Customers. Boston, MA: Harvard Business School Press.

Sigala, M. (2006). Mass customisation implementation models and customer value in mobile phones services: Preliminary findings from Greece. Managing Service Quality, 16(4), 395-420.

Simon, H. A. (1957). A Behavioral Model of Rational Choice. In Models of Man. New York: Wiley.

von Hippel, E. (2005). Democratizing Innovation. Cambridge \& London: The MIT Press. Wieland, K. (2006). The customer retention challenge. Telecommunications International,, vol. 40, Issue 10, pp. 8

Winter, R. (2001). Mass Customization and Beyond-Evolution of Customer Centricity in Financial Services. Proc. of the International NAISO Congress on Information Science Innovations (ISI'2001), ICSC Academic Press.

Xu, Y., \& Pitt, D. C. (2002). Chinese Telecommunications Policy. Norwood: Artech House.

Zeithaml, V. A., Parasuraman, A., \& Berry, L. L. (1985). Problems and Strategies in Services Marketing. Journal of Marketing, 49(2), 33-46. 


\section{Publications in the Report Series Research ${ }^{*}$ in Management}

\section{ERIM Research Program: "Business Processes, Logistics and Information Systems"}

2007

India: a Case of Fragile Wireless Service and Technology Adoption?

L-F Pau and J. Motiwalla

ERS-2007-011-LIS

http://hdl.handle.net/1765/9043

Some Comments on the Question Whether Co-occurrence Data Should Be Normalized

Ludo Waltman and Nees Jan van Eck

ERS-2007-017-LIS

http://hdl.handle.net/1765/9401

Extended Producer Responsibility in the Aviation Sector

Marisa P. de Brito, Erwin A. van der Laan and Brijan D. Irion

ERS-2007-025-LIS

http://hdl.handle.net/1765/10068

Logistics Information and Knowledge Management Issues in Humanitarian Aid Organizations

Erwin A. van der Laan, Marisa P. de Brito and S. Vermaesen

ERS-2007-026-LIS

http://hdl.handle.net/1765/10071

Bibliometric Mapping of the Computational Intelligence Field

Nees Jan van Eck and Ludo Waltman

ERS-2007-027-LIS

http://hdl.handle.net/1765/10073

Approximating the Randomized Hitting Time Distribution of a Non-stationary Gamma Process

J.B.G. Frenk and R.P. Nicolai

ERS-2007-031-LIS

http://hdl.handle.net/1765/10149

Application of a General Risk Management Model to Portfolio Optimization Problems with Elliptical Distributed Returns for Risk Neutral and Risk Averse Decision Makers

Bahar Kaynar, S. Ilker Birbil and J.B.G. Frenk

ERS-2007-032-LIS

http://hdl.handle.net/1765/10151

Optimal Zone Boundaries for Two-class-based Compact 3D AS/RS

Yugang Yu and M.B.M. de Koster

ERS-2007-034-LIS

http://hdl.handle.net/1765/10180

Portfolios of Exchange Relationships: An Empirical Investigation of an Online Marketplace for IT Services

Uladzimir Radkevitch, Eric van Heck and Otto Koppius

ERS-2007-035-LIS

http://hdl.handle.net/1765/10072

From Closed-Loop to Sustainable Supply Chains: The WEEE case

J. Quariguasi Frota Neto, G. Walther, J.Bloemhof, J.A.E.E van Nunen and T.Spengler

ERS-2007-036-LIS

http://hdl.handle.net/1765/10176 
A Methodology for Assessing Eco-Efficiency in Logistics Networks

J. Quariguasi Frota Neto, G. Walther, J.Bloemhof, J.A.E.E van Nunen and T.Spengler

ERS-2007-037-LIS

http://hdl.handle.net/1765/10177

Strategic and Operational Management of Supplier Involvement in New Product Development: a Contingency Perspective Ferrie E.A. van Echtelt, Finn Wynstra and Arjan J. van Weele

ERS-2007-040-LIS

http://hdl.handle.net/1765/10456

How Will Online Affiliate Marketing Networks Impact Search Engine Rankings?

David Janssen and Eric van Heck

ERS-2007-042-LIS

http://hdl.handle.net/1765/10458

Modelling and Optimizing Imperfect Maintenance of Coatings on Steel Structures

R.P. Nicolai, J.B.G. Frenk and R. Dekker

ERS-2007-043-LIS

http://hdl.handle.net/1765/10455

Human Knowledge Resources and Interorganizational Systems

Mohammed Ibrahim, Pieter Ribbers and Bert Bettonvil

ERS-2007-046-LIS

http://hdl.handle.net/1765/10457

Revenue Management and Demand Ful Ilment: Matching Applications, Models, and Software

Rainer Quante, Herbert Meyr and Moritz Fleischmann

ERS-2007-050-LIS

http://hdl.handle.net/1765/10464

Mass Customization in Wireless Communication Services: Individual Service Bundles and Tariffs

Hong Chen and Louis-Francois Pau

ERS-2007-051-LIS

Individual Tariffs for Mobile Services: Analysis of Operator Business and Risk Consequences

Hong Chen and Louis-Francois Pau

ERS-2007-052-LIS

Individual Tariffs for Mobile Services: Theoretical Framework and a Computational Case in Mobile Music

Hong Chen and Louis-Francois Pau

ERS-2007-053-LIS

Individual Tariffs for Mobile Communication Services

Hong Chen and Louis-Francois Pau

ERS-2007-054-LIS

\footnotetext{
* A complete overview of the ERIM Report Series Research in Management: https://ep.eur.nl/handle/1765/1

ERIM Research Programs:

LIS Business Processes, Logistics and Information Systems

ORG Organizing for Performance

MKT Marketing

F\&A Finance and Accounting

STR Strategy and Entrepreneurship
} 